\title{
Pedagogic Dilemma for History Education: Voices of Student
}

\section{Teachers in Lesotho}

\author{
Raymond N. Fru ${ }^{1 *}$ \\ ${ }^{1}$ Department of Languages and Social Education, Faculty of Education, National University of Lesotho \\ P.O. Roma, 180, Lesotho \\ *Raymond N. Fru, E-mail: fru_nkwenti@yahoo.com
}

\begin{abstract}
It is no secret that history education in many parts of the world is facing immense challenges. This academic discipline has never been under more pressure to justify its place in the curriculum of many educational systems. While some systems such as South Africa have overtly downplayed the importance of the discipline through unfavorable curriculum implementations over the years since the dawn of democracy, other systems like Lesotho have adopted more covert strategies to systematically out-phasing history education in the secondary and high schools. The result in the case of Lesotho is that the subject is very unpopular in secondary and high schools as the number of schools teaching the subject has dwindled drastically over the years. The situation is exacerbated by poor Junior Certificate (JC) examination results for the few schools that teach the subject.

Against this backdrop, this article engages the discourses around the status of history education in the context of Lesotho from a student teacher's perspective. While many studies have focused on the role of students, government departments and school administrations in explaining the negative position of history education, the stance in this article is that the role of the history teacher is as vital and cannot be undermined. Teachers' understanding of the objectives of history teaching and their attitudes towards the discipline has important implications for the way the discipline is perceived by students and the public. As a result, this article presents findings ofa study conducted with some novice history teachers in Lesotho on their understandings of the objectives of history teaching especially in a Lesotho context. Such understandings are then used as a basis to theorise the status of the discipline, but also to reflect on the future of history education in Lesotho.
\end{abstract}

\section{Keywords}

curriculum, history education, Lesotho, Pedagogy, teaching objectives

\section{Introduction}

In the words of the former president of South Africa-Nelson Mandela, "education is the most powerful weapon which you can use to change the world". In addition to that, it is the key to eliminating gender inequality, to reducing poverty, to creating a sustainable planet, to preventing 
needless deaths and illness, and to fostering peace. Moreover, in a knowledge economy, education is the new currency by which nations maintain economic competitiveness and global prosperity. As much as this statement is true for all countries in the world, it is even more relevant in the context of Lesotho. The Kingdom of Lesotho is a small, mountainous and landlocked country that is completely surrounded by South Africa. With a population of approximately 1.9 million and an annual growth rate of $0.9 \%$, Lesotho is classified as one of the Least Developed Countries in the world with a per capita income of $\$ 1879$ (United Nations Development Programme, 2013). The country is very young demographically and consists of a predominantly rural population that mostly depend on subsistence agriculture for their livelihoods. Owing to low agricultural productivity and with only $10 \%$ of its land surface available for arable agriculture, the country relies heavily on imports from South Africa.

The above challenges are just part of the plethora of problems plaguing Lesotho. In light of the above, Education has been considered a priority to address these challenges. The efforts of the Government in this regard is encapsulated in the Vision 2020 document in which it acknowledges that the present system of education hasn't yet responded to the needs of the country and commits "to develop an education system that is universal, free and compulsory to all" as well as to give priority to the "improvement of the management capacity of the education institutions at all levels and the reversal of the adverse effects of the HIV and AIDS pandemic on the education system" (Lesotho Vision, 2012).

The expectation therefore is that history education as a body of knowledge should form part of the plans to encourage education in Lesotho. This is however not the case as the continuous marginalization of the subject is evident in its dwindling offering in schools around the country. This is in spite of the undoubted values that an emphasis on the study of history will add to the lofty visions of the country going forward. It is in this light that the position of this article is that the objectives of teaching history from the perspective of teachers play a major role in the way the subject is perceived by students, other scholars and the general public.

\section{Literature}

There is very limited literature that has examined the nature of history education in Lesotho. Perhaps the most notable source comes from Ntabeni (2010). In this article, she examines the chequered nature of history at the level of primary schools. She explores the historical development of the discipline in Lesotho at primary school levels and concludes that it is a "far cry from the global move of exposing all learners to history teaching as early as their infant schooling" (p. 231). In line with the purpose of this article, Ntabeni (2010) sees an urgent need to prepare primary teachers for knowledge and understanding of the teaching and learning of history at both the pre and in-service stages. Such a call will definitely entail an evaluation of the objectives of teaching history from most importantly, the teacher's point of view. From a secondary school perspective, the same author above posits that history is the most unpopular subject in the social science group that also includes development studies, geography, and religious knowledge (Ntabeni, 2007). The figures supporting this claim is that in 2006, 
out of 230 and more Lesotho secondary and high schools, only 17 were still offering the subject and this few were apparently mainly doing so because their principals had a major in history (Ntabeni, 2007).

The picture explored above is highlighted further and even concurred by Fru (2015) who view's history education in Lesotho as being at the crossroads. His narration of experiences supervising student teachers on teaching practice in Lesotho secondary schools paints a sombre picture. Worthy of note though, are his recommendations for a turnaround strategy. These include: the compulsory implementation of history in all schools across the country; employment of specialist history staff to occupy history teaching positions; valorisation through staff training on the procedural nature of history; and promotion of research into history teaching.

\section{Methodology}

Naturally, all aspects of the teaching of history such as its aims, content, and methods, are vital elements needed to engage the reasons for the unpopularity of the discipline. However, the study that was conducted and is reported in this article, deals with only one of the problems highlighted above, being an investigation into the objectives of history teaching in Lesotho through the views and voices of history teachers on teaching practice. The assumption is that the goals of teaching any subject are necessary ingredients in achieving any desired outcome. Properly defined goals therefore will most likely lead to well-focused teaching and definitely encouraging output. Novice teachers were selected because they are the future of the discipline in Lesotho. Being fresh from training as history teachers, their views on the objectives of history teaching will not only give a foretaste of the future of the discipline in Lesotho but will also throw some light on the nature of their own training at University.

The study was done with the students through an administration of questionnaires. The questionnaire in question was an adaptation of a scale used by Adejunmobi (1975) in a similar study in which he investigated the objectives of history teaching in selected secondary schools in Western Nigeria. His study was, however broader in the sense that the subjects represented three categories of people involved in the teaching of history-university lecturers, teachers, and teacher trainees. It is the intention of this author to replicate a similar study in the future in a context of Lesotho. The framework consists of twelve statements of objectives that according to the author were the most frequent as perliterature reviewed in the field over the years. It is these statements of objectives that were presented to the respondents and constituted the main data collection strategy for this study. Below is a full list of these statements of objectives. First, I provide their abridged forms and then follow up with their explanations after the hyphen.

(1) Heritage - To introduce the students to their heritage by teaching them about their society — what it is, how it grows, the way it works, and what it has achieved.

(2) Historical knowledge or facts-To obtain historical knowledge or facts adequate for passing external examinations. 
(3) Critical thinking-To develop in students the ability to think critically through the weighing of evidence, discerning facts from fancy, and by being less susceptible to propaganda.

(4) Morals - To inculcate moral values so that the students develop good character when they hear or read about the great personalities of the past.

(5) Imagination - To quicken the imagination by an awareness in students of things and people not present to their senses and by taking part in experiences which are not their own.

(6) International understanding - To promote international understanding by emphasising the essential oneness of the human race in spite of our differences, and through the growing realisation of the interdependence of nations and peoples.

(7) Citizenship-To encourage good citizenship through teaching of local history and by developing a sense of active participation in the progressive activities of the society.

(8) Enjoyment-To encourage the worthy use of leisure by reading for pleasure books in history and in historical literature, visiting libraries and museums, visiting other places and countries of historical interest, and conversing with others of like interest.

(9) Tolerance-To help the pupils develop tolerance by being sympathetic to other individuals or groups who may belong to different ethnic groups or whose opinions may differ from theirs.

(10) Human understanding - To develop in the students' ability to understand human behaviour through the study of history, which is the "Humane study par excellence".

(11) Problem solving - To give students sound training in the recognition of cause and effect in solving political and socio-economic problems.

(12) Wisdom-To inculcate in the students modes of thought which may be called wisdom, such as ability to make right use of knowledge through their introduction to past controversies and the realisation that truth is seldom on one side alone.

The list of possible objectives for teaching history is in exhaustive. As stated earlier, this author settled on this framework that has been tested already in a previous similar study.

For each of the twelve objectives, the participants were required to respond twice. Firstly rating the objectives, as actually practiced in the schools (the observed rating), and secondly rating the objectives as they ought to be (the ideal rating). All these were to be done on a five-point scale as follows:

Table 1. Five Point Scale Ratings

\begin{tabular}{|c|c|c|c|}
\hline No & Objectives & Observed rating & Ideal rating \\
\hline 1 & Objectives which are least important & & \\
\hline 2 & Objectives which are relatively important & & \\
\hline 3 & Objectives which are of average importance & & \\
\hline 4 & Objectives which are quite important & & \\
\hline 5 & Objectives which are most important & & \\
\hline
\end{tabular}


The 40 respondents in this study had just completed a four months school based teaching practice exercise where they taught history together with a second major subject as per university requirement. Being fresh from university, the assumption is that these student teachers have a very strong mastery of recent theoretical constructs and discourses and developments underpinning history instruction. This puts them in a better position to share their understandings in terms of the "Ideal rating". Information on the observed rating was derived from their experiences during teaching practice. Summarily therefore, the statement of objectives in this study were measured against the student teachers' theoretical views on the discipline as acquired through engagements with their university subject courses and their experiences on the practical application as observed during their practice time.

In April 2015, after the end of the teaching practice exercise, 45 questionnaires were given out to the students upon their return to campus. These students had been spread to school in all the nine districts of the country and therefore had different contextual and practical experiences. Two weeks later 40 students returned their completed questionnaire making a $90 \%$ return ratio. This satisfactory return ratio paved the way for the analysis of the data.

Both quantitative and qualitative methods were used to analyse and interpret the data. Quantitative methods were used to show the statistical opinions of the participants about how important the objectives are in practice and again how they should be in an ideal situation. Through this method, it was possible to present the rankings of the various objectives on both the observed and the expected levels. On the other hand, qualitative analysis was relevant to provide an in-depth explanation and make meaning of the quantitative data. Table 1 and 2 that follows is a representation of the data on the mean of the 12 statements of objectives and the participants' ratings respectively.

Table 2. Representing Mean Observed and Expected Ratings of the 12 Statements of Objectives

\begin{tabular}{lll}
\hline Statements of Objectives & Mean Observed Rating N=40 & Mean Expected Rating N=40 \\
\hline 1. Heritage & 2.72 & 3.72 \\
2. Historical Knowledge or Facts & 4.20 & 4.07 \\
3. Critical Thinking & 1.40 & 3.02 \\
4. Morals & 2.25 & 1.97 \\
5. Imagination & 2.07 & 2.07 \\
6. International Understanding & 2.72 & 2.95 \\
7. Citizenship & 3.07 & 3.27 \\
8. Enjoyment & 1.50 & 2.90 \\
9. Tolerance & 1.90 & 3.15 \\
10. Human Understanding & 2.40 & 2.32 \\
11. Problem solving & 1.42 & 3.32 \\
12. Wisdom & 1.57 & 1.50 \\
\hline
\end{tabular}


Table 3. Representing Ranks, Observed and Expected, of the 12 Statements of Objectives of History Teaching Obtained from Ratings by Student Teachers

\begin{tabular}{lll}
\hline Statements of Objectives & Rank Observed & Rank Expected \\
\hline 1. Heritage & 3.5 & 2 \\
2. Historical Knowledge or Facts & 1 & 1 \\
3. Critical Thinking & 12 & 6 \\
4. Morals & 6 & 11 \\
5. Imagination & 7 & 10 \\
6. International Understanding & 3.5 & 7 \\
7. Citizenship & 2 & 4 \\
8. Enjoyment & 10 & 8 \\
9. Tolerance & 8 & 5 \\
10. Human Understanding & 5 & 9 \\
11. Problem solving & 11 & 3 \\
12. Wisdom & 9 & 12 \\
\hline
\end{tabular}

\section{Discussions}

The tables two and three above summarises the results of the questionnaires. The discussion of these results does not consider each and every objective. Rather only those considered having considerable statistical significance to this study are engaged with.

The most obvious pattern from the data is the perfect agreement on "historical knowledge or facts" being the most important objective both at the observed and the expected level. The interpretation of this finding is that the student teachers not only observed that history teaching was dominated by historical facts, but that their own convictions about what constitutes historical knowledge are in line with their observations. Therefore, the teaching of historical facts forms the backbone of history teaching in Lesotho schools.

However, the implication of this realisation is huge and massive. Importantly, there is the fact that the procedural aspects of history are clearly sacrificed on the altar of historical content knowledge. The importance of developing a holistic approach to historical understanding that constitutes a mastery of both substantive and procedural knowledge has been acknowledged by several authors (Brooks, Aris, \& Perry; Fru, 2015; Kitson, Pandry, \& Husbands, 2003). The inclination towards substantive knowledge of history in Lesotho schools provides a clue to the bigger dilemma facing the discipline in the country. This can be explained further with the assertion by Wineburg (2001) that too much content in class without procedure and engagement results in a scenario where students "... sit mute and glassy eyed, a few scribbling notes but most yawning in boredom" (p. 217). It can therefore be argued that the emphasis on substantive knowledge of history has transformed history into a boring discipline in 
Lesotho schools.

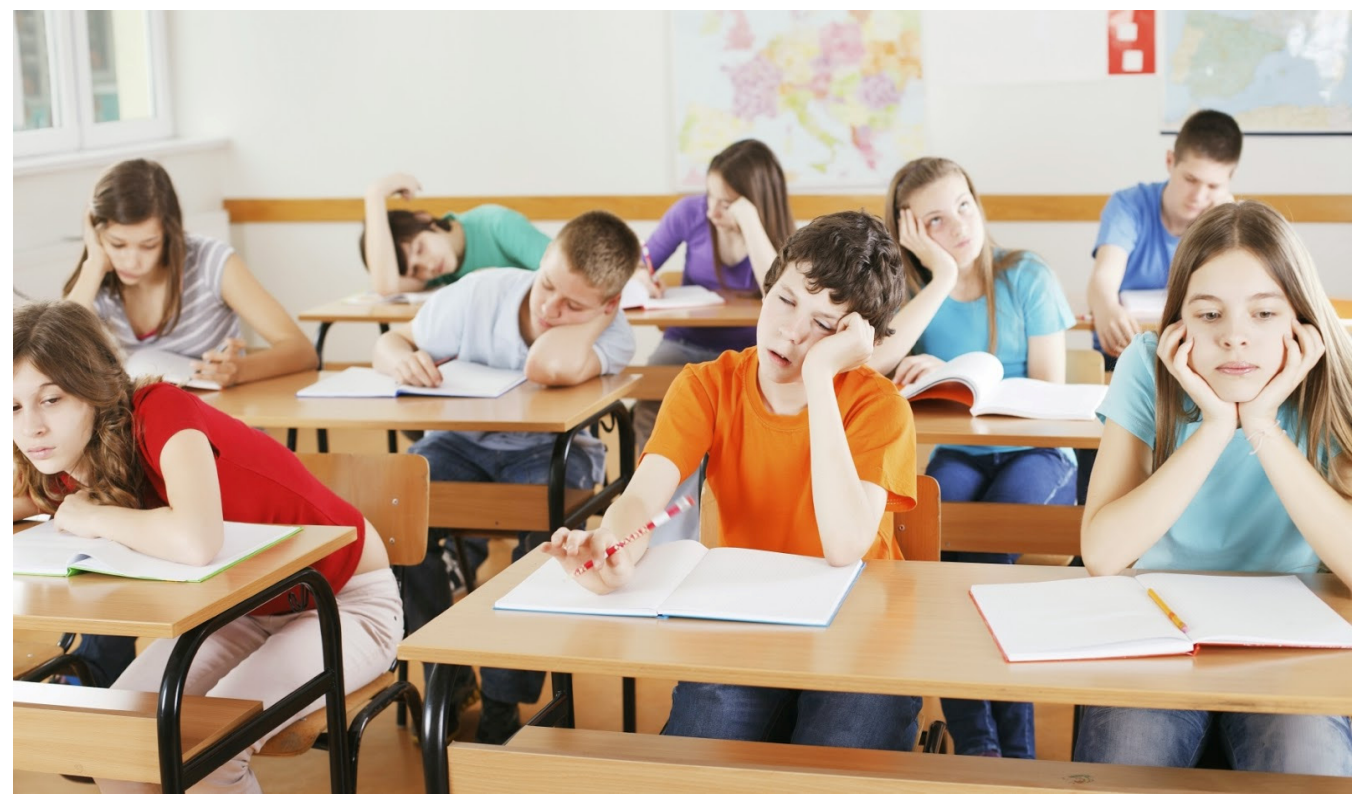

Figure 1. Visual Illustration of a Boring History Lesson Resulting from a High Emphasis on Substantive Knowledge of History

Source: Boutin, J. (2014). How standards based instruction is murdering schools: an urban teacher's education.

Retrieved

from

http://www.anurbanteacherseducation.com/2014/01/how-standards-based-instruction-is.html

However, a critical appraisal of the Lesotho Junior Certificate-History Curriculum provides an explanation to where the problem emanates. I present below the full list of general as well as specific objectives of that curriculum to show how its focus on content knowledge at the expense of other aspects of historical understanding creates the kind of environment for history education explained in the preceding paragraph.

The General Objectives of the curriculum are as follows:

(1) Have acquired knowledge, skills and attitudes from the history of Lesotho.

(2) Have acquired knowledge and understanding of regional history and the world.

(3) Have acquired knowledge and attitudes of environmental changes and historical developments.

(4) Have acquired knowledge of the historical background of population growth and distribution over time.

(5) Have developed an awareness and appreciation of the main existing religions of the world.

(6) Have developed knowledge and understanding of regional and international organizations (Lesotho Ministry Of Education and Training (MOET), 2004).

These six general Objectives are immediately followed by 12 Specific Objectives which are:

(1) Demonstrate knowledge of the social, political and economic developments in the history of Published by SCHOLINK INC. 
Lesotho.

(2) Develop love and loyalty to Lesotho.

(3) Develop appreciation of their cultural heritage, beliefs and values.

a) Demonstrate knowledge of the events in the histories of selected SADC countries;

b) Demonstrate knowledge of selected events in the history of the world;

c) Demonstrate knowledge of historical developments of man's interaction with the environment;

d) Develop appreciation for the need to preserve the environment;

e) Demonstrate knowledge of population growth, distribution and movement over time and their impact on available resources;

f) Demonstrate knowledge of the main religions of the world and the role they played in the histories of other societies around them;

g) Develop tolerance, and appreciation of other societies' beliefs and values;

h) Demonstrate knowledge of the United Nations Organisation, its agencies and their activities in Lesotho;

r) Demonstrate knowledge of the basic human rights as reflected in the Universal declaration of human rights (Lesotho Ministry Of Education and Training (MOET), 2004).

The curriculum is clearly silent on historical inquiry skills as an objective for teaching history in Lesotho. It is therefore this silence that translates into classroom practice by teachers as observed by the student teachers in this study. This can be corroborated by the fact that other objectives of a procedural nature, such as critical thinking and problem solving scored the least ratings in the observed objectives.

Furthermore, there is the factor of the end of course exams that count to explain reliance on facts of history. This again is linked to the Junior Certificate Curriculum and even the Lesotho General certificate of Secondary Education-History (Lesotho Ministry Of Education and Training (MOET), 2004/2014). The Junior Certificate, for example, provides a scheme for assessment that is divided into 4 sections as follows:

Section A-Multiple choice;

Section B-Ballad questions;

Section C-Short essays;

Section DE_-Long essays.

From the above assessment rubric, it can be noted that the expectation for students at the end of the course in Form $\mathrm{C}$ is on how much historical content in the form of facts they have grasped and are able to reproduce in the form of exams. In line with this, is the tendency in Lesotho as in many other African countries to judge the worth of a school by its percentage pass or pass rate at end of course examinations. This public pressure on the school results in them focusing their teaching and learning entirely around the expectations of the exams and in the case of history, this is done at the expense of other elements that inform historical knowledge but difficult to assess because they are less factual. 
Moreover, the fact that the ideal or expected ratings also see's historical knowledge or facts in first position may lead one to suggest the teacher's reliance on the advantages of inertia. This means that these student teachers were introduced to history at different levels (secondary or tertiary) through fact-memorisation and therefore they find it more convenient and are happy to teach in exactly the same way. To them, the reflective and student centered approach to teaching history would burden them with far more work compared to the relatively easier teaching of facts only. However, this is not necessarily the case because other student centered objective are highly rated and ranked in the expected category. These include: problem solving rated 3.32, ranked 6 and critical thinking, rated 3.02 with a ranking of 6 . Implying that critical thinking and problem solving skills are as important for history teaching as is mastery of content and facts about the past.

The ratings also show high rankings for the citizenship, international understanding, and heritage objectives for the observed category. Again, these three objectives form part of the curriculum objectives that I have cited earlier in this article and are very much in line with developments around the history of Lesotho. Lesotho's history is largely intertwined with that of the Republic of South Africa. Against colonial odds especially from the Boersand the British, King Moshoeshoe 1 succeeded to build a stable and united Basotho Nation. However, the tensions with these colonial powers resulted in conflicts and eventual loss of territory that Moshoeshoe considered part of his Nation (Mothibe \& Ntabeni, 2002). This explains why linguistically, the Sotho language which is the indigenous language of the Basotho is also one of the eleven official languages of South Africa as part of this intertwined historical relationship. These, coupled with the fact that present day Lesotho is landlocked, completely surrounded by South Africa have ensured that the survival of Lesotho as a nation cannot be detached from relations with the outside world. Hence, the focus on history teaching, serving the interest of promoting the national heritage, encouraging citizenship and enhancing an understanding of the world outside Lesotho. Except for International Understanding, the other two Objectives above show consensus at the expected category.

This author thinks it is very relevant to give relevance to these three objectives in view of the recent political tensions that Lesotho has witnessed. In 2014 an attempted coup threatened to plunge the country into civil war if not of some timely SADC mediation BBC News (30 August, 2014). Ever since then, the political atmosphere in the country has remained tensed and volatile at best.

Another objective that is not practiced, but which the student teachers see as ideal is tolerance. This objective is given an observed rating of 1.90, rank number eight implying a lack of implementation of activities in the teaching of history that promotes tolerance. However, the expected rating for tolerance stands at 3.15 on rank number five. This could be explained in relation to the difficult political environment that the country has witnessed since 2014. The students, therefore, think that history education should play a role in creating spaces and opportunities for tolerance as a recipe for a return to peace and national stability. For this to happen, a student centered approach will have to be encouraged where by historical content information is provided through multiple sources so that students can be 
encouraged to engage and critique the content through multiple perspectives. This is based on my assumption that tolerance is only possible when there is open-mindedness in appreciating the content.

\section{Conclusion}

There is no doubting the fact that the teaching of history in Lesotho schools is plagued with challenges. From many secondary schools choosing not to offer the discipline, to low enrollments in schools that offer it, the dwindling status of the discipline in Lesotho just keeps getting worse. Investigations to this dilemma reveal that a great extent of the problem lies in the classroom processes of instruction. Poor instruction strategies have over the years resulted in lack of interest to pursue the discipline by students or even by their parents.

The view in this article is that there is a direct correlation between teachers' perceptions on the objectives of history and the way they teach history in the classrooms. Consequently, the study in this article was conducted with some 40 student teachers who had just completed a three months teaching practice exercise in schools across Lesotho. The study presented them with 12 a priori objective for teaching history in schools in which they were required to rate in order of importance. The ratings were also done in two categories, that is, their observations in the schools and their expectations.

The results revealed that history teaching in Lesotho was dominated by substantive knowledge in the form of memorisation of facts about the past at the expense of other objectives viewed as procedural such as problem solving. This in turn partially explains why the discipline is not taken seriously if one believes the assumption that "everybody can tell a story". However, a more than favourable rating for procedural processes of history under the ideal category suggests that the student teachers have training in holistic teaching of history, but the problem lies in the implementation or the curriculum. This means stakeholders need to review the curriculum in terms of its relation to historical knowledge. It also means refresher courses have to be organised constantly to keep teachers abreast with recent developments and theories regarding the teaching of history.

\section{References}

Adejunmobi, S. A. (1975). Objectives of history teaching in Western Nigeria high schools. The History Teacher, 8, 421-436.

BBC News. (2014, August 30). Lesotho "coup" forces PM Thabane to South Africa. Retrieved September 2, 2015, from http://www.bbc.com/news/world-africa-28994193

Boutin, J. (2014). How standards based instruction is murdering schools: An urban teacher's education. Retrieved September 27, 2015 , from http://www.anurbanteacherseducation.com/2014/01/how-standards-based-instruction-is.html

Brooks, R., Aris, A., \& Perry, I. S. (1993). The effective teaching of history. London: Longman.

Fru, R. N. (2015). History education at the crossroads: Challenges and prospects in a Lesotho context. Yesterday \& Today, 13, 67-82. 
Kitson, A., Pendry, A., \& Husbands, C. (2003). Understanding history teaching: Teaching and learning about the past in secondary schools. Maidenhead; Open University Press.

Lesotho Ministry Of Education and Training (MOET). (2004). Lesotho Junior Certificate-History. Maseru, Lesotho: National Curriculum Development Centre.

Lesotho Ministry Of Education and Training (MOET). (2014). Lesotho General Certificate of Secondary Education-History Syllabus 0184. Maseru, Lesotho: National Curriculum Development Centre.

Lesotho Vision. (n.d.). Lesotho Government Website. Retrieved October 16, 2015, from http://www.gov.ls/home/default.php

United Nations Development Programme. (2013). Lesotho Millennium Development Goals Report-2013. $\quad$ Retrieved $\quad$ October 16, 2015, from http://www.ls.undp.org/content/lesotho/en/home/library/mdg/lesothomdgreport2013.html

Mothibe, T., \& Ntabeni, M. (2002). The role of the Missionaries, Boers and British in social and territorial changes, 1833-1868. In N. W. Pule, \& M. Thabane (Eds.), Essays on aspects of the political economy of Lesotho 1500-2000 (pp. 35-57). Maseru: Morija Printing Works.

Ntabeni, M. N. (2007). History teaching, learning and Junior Certificate (JC) examination results in Lesotho, 2000-2006: Implications for teacher education. Yesterday \& Today, 1, 218-238.

Ntabeni, M. N. (2010). History education in the primary schools of Lesotho. Education 3-13: International Journal of primary, Elementary and Early Secondary Education, 38, 225-232.

Wineburg, S. (2001). Lost in words: Moral ambiguity in the history classroom. In S. Wineburg (Ed.), Historical thinking and other unnatural acts: Charting the future of teaching the past. Philadelphia, PA: Temple University Press. 